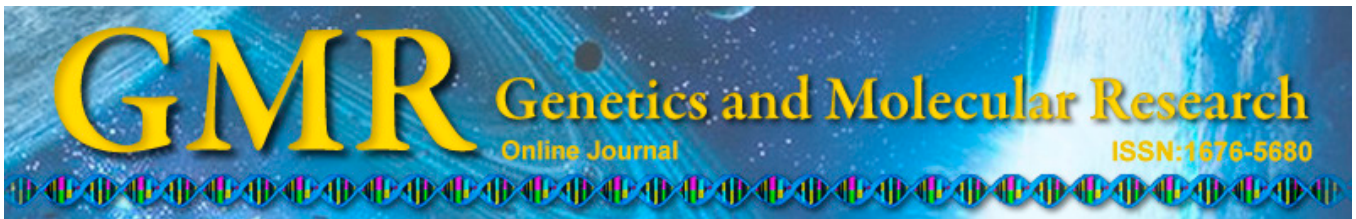

\title{
BRAF overexpression is associated with BRAF V600E mutation in papillary thyroid carcinomas
}

\author{
R.C. da Silva ${ }^{1,2}$, H.S.C. de Paula ${ }^{1,2}$, C.B.Q.S. Leal ${ }^{1}$, B.C.R. Cunha ${ }^{3}$, \\ E.C. de Paula ${ }^{2}$, R.C.G. Alencar ${ }^{2}$, A.J. Meneghini' ${ }^{2}$, A.M.T.C. Silva ${ }^{1}$, \\ A.P. Gontijo ${ }^{2}$, I.J. Wastowski ${ }^{4}$ and V.A. Saddi ${ }^{1,2}$ \\ ${ }^{1}$ Programa de Mestrado em Genética e Programa de Mestrado em Ciências \\ Ambientais e Saúde, Pontifícia Universidade Católica de Goiás, Goiânia, GO, Brasil \\ ${ }^{2}$ Hospital Araújo Jorge, Associação de Combate ao Câncer em Goiás, Goiânia, \\ GO, Brasil \\ ${ }^{3}$ Instituto de Patologia Tropical e Saúde Pública, Universidade Federal de Goiás, \\ Goiânia, GO, Brasil \\ ${ }^{4}$ Departamento de Biologia, Universidade Estadual de Goiás, Morrinhos, GO, \\ Brasil
}

Corresponding author: R.C. da Silva

E-mail: rcsilvaf@gmail.com

Genet. Mol. Res. 14 (2): 5065-5075 (2015)

Received July 29, 2014

Accepted December 10, 2014

Published May 12, 2015

DOI http://dx.doi.org/10.4238/2015.May.12.9

\begin{abstract}
A common mutation in the $B R A F$ gene, comprising the T1799A nucleotide transversion, which leads to the V600E amino acid substitution in the BRAF protein, has been observed in about $50 \%$ of papillary thyroid carcinomas (PTCs). However, BRAF protein expression has been rarely examined in such tumors. Clinical studies have shown important associations between $B R A F$ mutation and clinical parameters in PTC, such as progression, invasion, and recurrence. The aim of this study was to evaluate the association between BRAF protein overexpression and the BRAF V600E mutation in a group of
\end{abstract}


PTC patients. The study group included 116 patients with PTC from Araújo Jorge Hospital, Goiânia, Goiás, Brazil. Immunohistochemistry was utilized to analyze BRAF protein expression. Presence of the BRAF V600E mutation was determined by polymerase chain reaction amplification and restriction fragment length polymorphism, and confirmed by direct sequencing. The chi-square test with Yates correction and the Fisher exact test were used for statistical analysis. BRAF overexpression was detected in 55 patients with PTC (47.4\%) and the BRAF V600E mutation was observed in 74 patients $(63.8 \%)$. In the studied group, significant associations were observed between the BRAF V600E mutation and BRAF protein overexpression $(\mathrm{P}=0.0115)$, and also between BRAF overexpression and extra-thyroid extension of the tumor $(\mathrm{P}=0.0111)$. This study demonstrated a significant association between BRAF overexpression and the BRAF V600E mutation in PTC, highlighting the importance of these molecular events in the process of PTC carcinogenesis.

Key words: BRAF protein; Papillary thyroid carcinoma; BRAF; V600E mutation

\section{INTRODUCTION}

Thyroid cancer is the most common malignant endocrine neoplasia (Salvatore et al., 2006; Sipos and Mazzaferri, 2010), accounting for approximately 1\% of all human cancers. The incidence of these tumors is increasing worldwide. Malignant tumors of the thyroid are classified according to histological and clinical parameters and papillary thyroid carcinomas (PTCs) represent about $80 \%$ of these cases (Gheriani, 2006).

A common mutation in the BRAF gene has been observed in PTC. It comprises a T1799A nucleotide transversion within exon 15, and is detected in over $50 \%$ of PTCs (Sipos and Mazafferri, 2010). The T1799A mutation leads to the substitution of a valine residue at position 600 of the protein for a glutamate residue (V600E), with consequent gain of function and constitutive activation of the mitogen activated protein kinase (MAPK) pathway (Wojciechowska and Lewinski, 2006). The MAPK pathway is a signal transduction cascade driven by phosphorylation that connects growth factors and their respective cell surface receptors to intracellular responses such as cell proliferation (Vidwans et al., 2011). It is believed that BRAF overexpression can also result in overactivation of the MAPK pathway (Feng et al., 2011). Clinical studies have shown an association between BRAF mutation and clinical progression, invasion, and recurrence in PTC (Xing et al., 2005; Xing, 2010). However, there are still only a limited number of studies showing $B R A F$ gene expression in PTC, although this type of study can provide relevant information about the contribution of $B R A F$ to the pathogenesis of PTCs (Feng et al., 2011; Li et al., 2012a).

The identification of more accurate prognostic factors for PTCs represents an important opportunity aimed at providing new diagnostic and therapeutic decision options for PTC patients (Brose et al., 2009). In this study, the association between the BRAF V600E mutation and BRAF protein overexpression was investigated in PTC patients. 


\section{MATERIAL AND METHODS}

\section{Ethical considerations}

The protocol was reviewed and approved by the Ethics Committee of Araújo Jorge Hospital in Goiânia, Goiás, Brazil. This is a retrospective study that used data obtained from clinical records and formalin-fixed paraffin-embedded tumor samples.

\section{Selection of PTC cases}

The study group included 116 cases of metastatic and non-metastatic PTCs from the archives of the Pathology Department of Araújo Jorge Hospital. The selected cases were those of patients submitted to surgery between 2000 and 2005. Tumor samples were analyzed for histopathological diagnostic confirmation according to the classification of thyroid malignancies (ATA Taskforce et al., 2009). Patients included in the study presented a proven histopathological PTC diagnosis, available paraffin blocks, and also clinical data, including age, gender, tumor size, lymph node metastasis, distant metastasis, and extrathyroidal extension. Clinicopathological data were collected from medical records and used to generate a database. A total of 64 non-metastatic PTCs were selected in the first 2 years of the study (2000 and 2001), while the metastatic cases were selected over a period of 5 years (2000 to 2005). The biological specimens analyzed in this study consisted of PTC fragments collected through surgery, before any chemotherapy or radiation therapy.

\section{Immunohistochemistry}

The tumor fragments analyzed were fixed in $10 \%$ buffered formalin and embedded in paraffin blocks. After confirmation of the diagnosis, slides were prepared for immunohistochemical analysis. Section thickness was $3 \mu \mathrm{M}$. Immunohistochemical analysis was performed using the polymer immunoperoxidase-associated method (MACH 4 system, Biocare Medical, Concord, CA, USA) and was employed for the detection of BRAF protein levels by using a BRAF antibody (F-7 clone, 1:150; Santa Cruz Biotechnology Inc., Santa Cruz, CA, USA). Slides were incubated at $4{ }^{\circ} \mathrm{C}$ overnight with antibody diluted in phosphate-buffered saline, $\mathrm{pH} 7.4$, containing $1 \%$ bovine serum albumin. BRAF protein expression analysis was performed by counting tumor cells with cytoplasmic staining in the tumor areas of greatest staining. The proportion of tumor cells positive for BRAF staining was examined in 3-5-mm microscopic fields at 400X magnification under light microscopy. Wherever possible, the cell count was performed in three fields. Only the diffuse cytoplasmic staining of tumor cells was considered; positively stained stromal and inflammatory cells were not considered in this evaluation. The samples were divided into two BRAF staining groups: $<50$ and $\geq 50 \%$, according to an established cutoff obtained by a receiver operating characteristic curve, defined based on the immunohistochemical marking of BRAF and the presence of V600E mutation in the BRAF gene (Figure 1).

\section{DNA extraction and molecular analysis of the BRAF V600E mutation}

DNA extraction was performed using the Wizard Genomic DNA Purification Kit (Promega Corporation, Madison, WI, USA), according to manufacturer recommendations. 
The V600E $B R A F$ gene mutation was analyzed according to the procedure of Cohen et al. (2003). Specific primers for exon 15 of the $B R A F$ gene (5'-TCA TAA TGC TTG CTC TGA TAG G-3' and 5'-GGC CAA AAA TTT AAT CAG TGG A-3') were used to amplify a 224-bp gene fragment. The fragments were digested by the restriction endonuclease $T s p \mathrm{RI}(10 \mathrm{U} / \mu \mathrm{L}$; New England Biolabs, Beverly, MA, USA), which was used to identify the T1799A BRAF mutation as follows. The TspRI enzyme digested the 224-bp polymerase chain reaction (PCR) product to produce three major bands from the wild-type allele: 125,87 , and $12 \mathrm{bp}$. The T1799A mutation eliminated one of the Ts $p$ RI restriction sites, resulting in a 212-bp band from the mutant allele and residual bands from the wild-type allele.

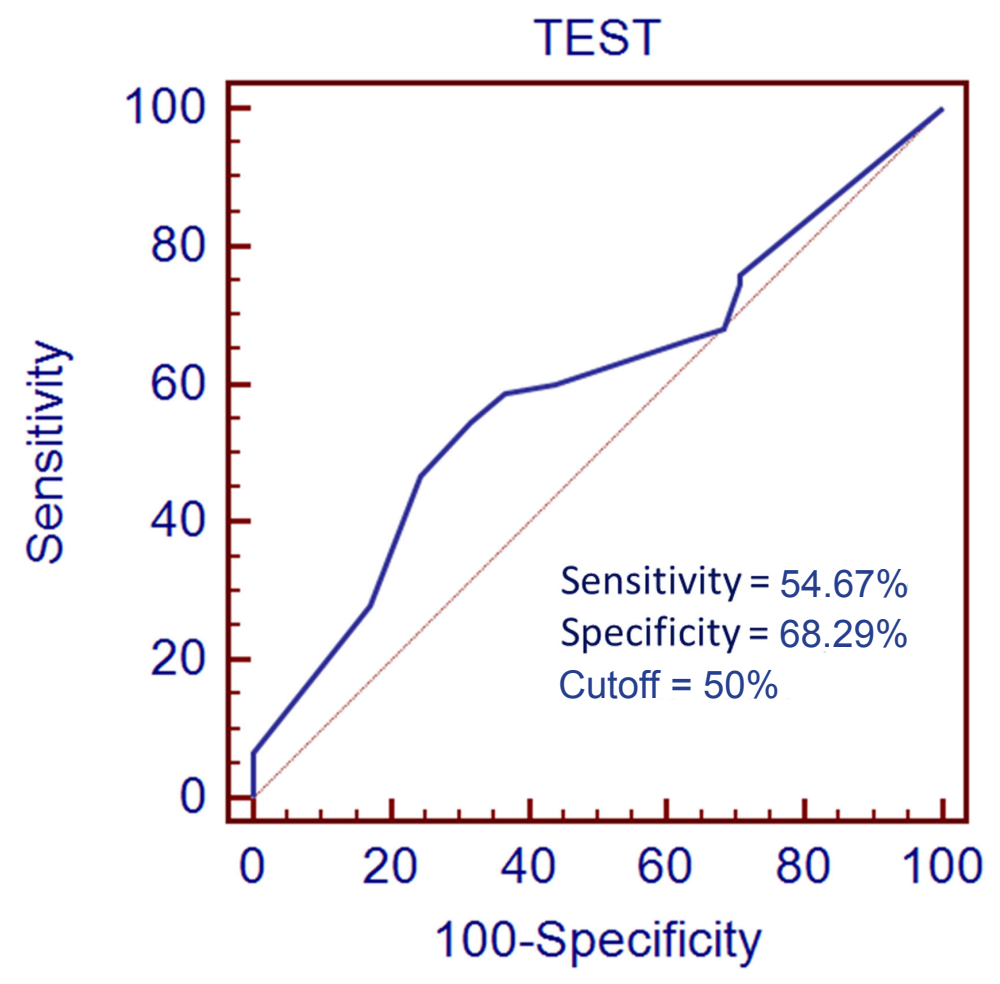

Figure 1. Receiver operating characteristic curve. Area under the curve $=0.509$.

To confirm the mutation results, automated sequencing was conducted at the Laboratory of Oncogenetics and Radiobiology, Hospital Araújo Jorge, in Goiânia, Brazil. The PCR products were first subjected to purification using the PureLink Quick Gel Extraction and PCR Purification Combo Kit (Invitrogen, Carlsbad, CA, USA) to remove dNTPs and primers, followed by nucleotide primer extension, using the BigDye Terminator v. 3.1 Ready Reaction Cycle Sequencing Kit (Applied Biosystems, Foster City, CA, USA). The sequencing reaction products were subjected to purification using BigDye Xterminator (Applied Biosystems) for complete removal of ddNTPs followed by capillary electrophoresis on an Applied Biosystems 3130xl DNA Analyzer. Mutations were identified by visual analysis of the sequence chromatograms (Figure 2) using the Seqscape Software v2.6 (Applied Biosystems). 


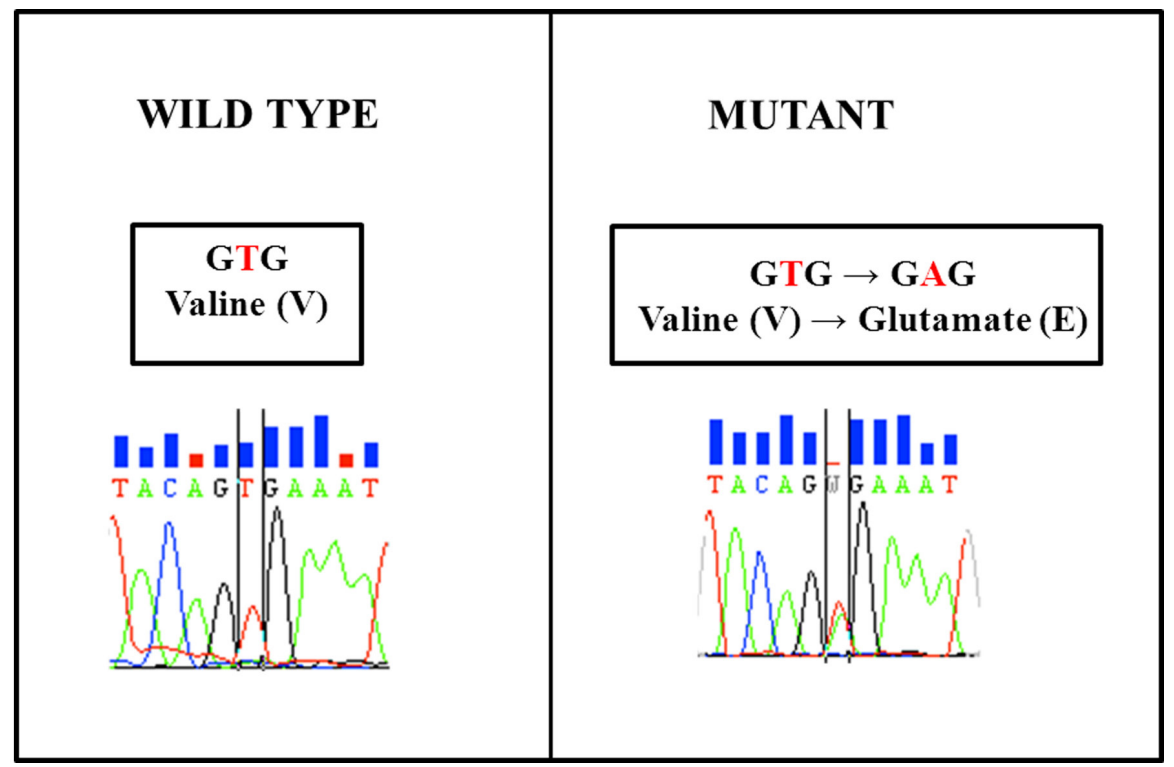

Figure 2. Wild-type and mutant sequence chromatograms of BRAF exon 15 (portion). The PTC BRAF mutationpositive sample (mutant) shows the heterogeneous thymine-to-adenine transversion at nucleotide position 1799, which results in a valine-to-glutamate substitution at residue 600 (BRAF V600E mutation rs113488022). PTC $=$ papillary thyroid carcinoma.

\section{Statistical analysis}

A database was developed of clinical and pathological features from patients diagnosed with PTCs using the Microsoft Excel software (Microsoft Corp., Redmond, WA, USA). For comparative analyses, the chi-square test (with Yates correction and a significance level of 5\%) was utilized; the Fisher exact test was employed when the frequencies in one or more cells were five or less.

\section{RESULTS}

\section{Study group}

Data from 116 patients with PTC, including 88 (76.0\%) women and 28 (24.0\%) men, were analyzed in this study. Patient ages ranged from $13-83$ years (median age of 36.8 years). Tumor size ranged from $0.4-8.5 \mathrm{~cm}$ (mean, $2.6 \mathrm{~cm}$ ). Fifty-two patients $(45.0 \%)$ had lymph node metastasis, of which three patients had distant metastases, including one in the bones, one in the central nervous system, and one in the skull and lungs. Among the studied cases, tumor growth with extrathyroidal extension was observed in 70 instances $(60.0 \%)$.

\section{V600E mutation analysis and immunohistochemical detection of BRAF in PTC}

Among 116 evaluated carcinomas, the BRAF V600E mutation was observed in 74 patients with PTC (63.8\%). In 61 patients (52.6\%), immunohistochemical detection of BRAF 
was observed in less than $50 \%$ of tumor cells (Figure 3A), and among these, 30 were negative for BRAF staining (Figure 3B). The remaining 55 patient samples $(47.4 \%)$ presented positive BRAF staining in $50 \%$ or more tumor cells, and were thus classified as overexpressed (Figure $3 \mathrm{C}$ and $\mathrm{D})$.

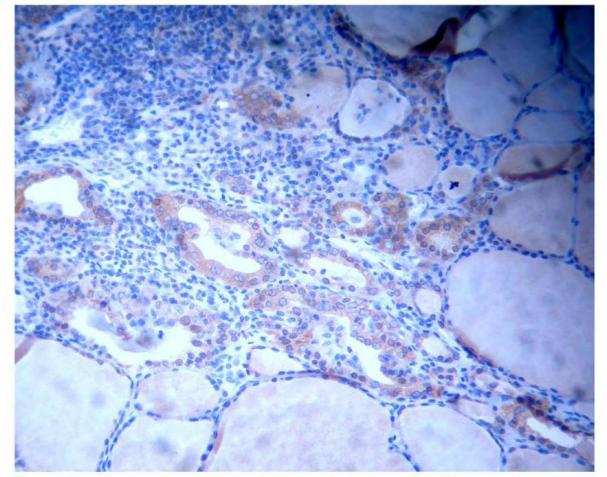

$\boldsymbol{A}$

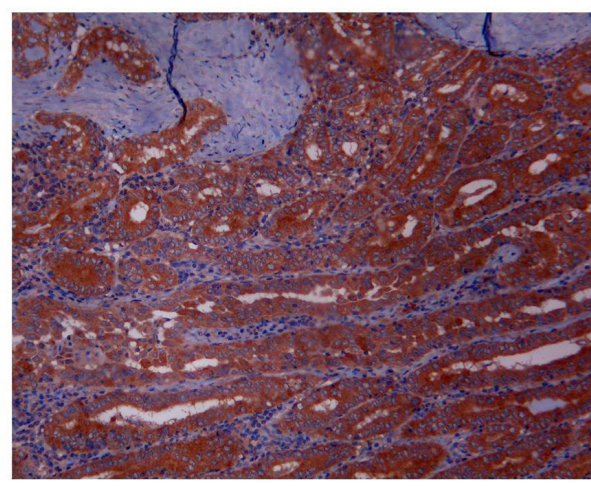

C

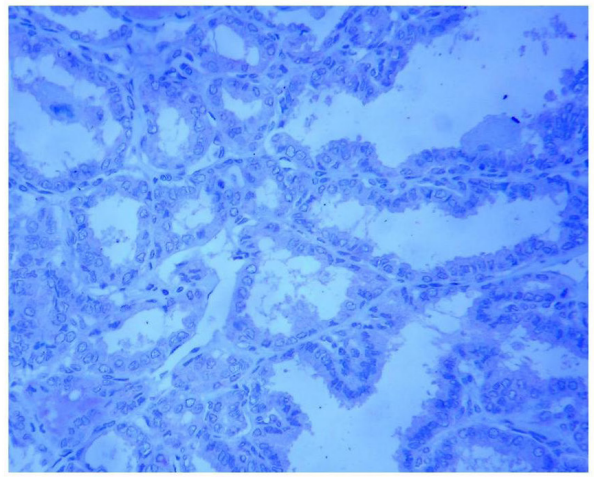

B

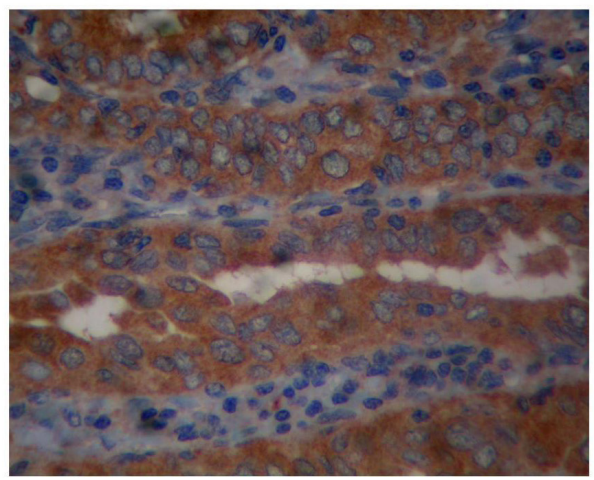

D

Figure 3. Photomicrography showing immunohistochemical profiles of BRAF detection. Positivity is indicated by the presence of brown color resultant from DAB (3,3'-diaminobenzidine tetrahydrochloride) precipitation. A. Positive staining in less than $50 \%$ of papillary thyroid carcinoma cells at $100 \mathrm{X}$ magnification; B. BRAF-negative papillary thyroid carcinoma at $100 \mathrm{X}$ magnification; C. positive staining in $50 \%$ or more papillary thyroid carcinoma cells at $100 \mathrm{X}$ magnification; and D. positive staining in $50 \%$ or more papillary thyroid carcinoma cells at $200 \mathrm{X}$ magnification.

\section{Associations between BRAF protein immunodetection, BRAF V600E mutation, and PTC clinical and pathological aspects}

Table 1 shows the investigated associations between PTC clinical and pathological aspects and BRAF protein overexpression. In this study, a significant association was observed between the V600E BRAF mutation $(\mathrm{P}=0.0115)$ and $\mathrm{BRAF}$ protein overexpression as well as between BRAF overexpression and extrathyroidal extension of the tumor $(\mathrm{P}=0.0111)$. 


\begin{tabular}{|c|c|c|c|c|c|}
\hline Criteria & BRAF $<50 \%$ & $\mathrm{BRAF} \geq 50 \%$ & $\mathrm{~N}$ & $\mathrm{P}$ & Test \\
\hline \multicolumn{6}{|l|}{ Gender } \\
\hline Female & $42(47.7 \%)$ & $46(52.3 \%)$ & 88 & \multirow[t]{2}{*}{0.063} & \multirow[t]{2}{*}{$\chi^{2}$} \\
\hline Male & $19(67.9 \%)$ & $9(32.1 \%)$ & 28 & & \\
\hline \multicolumn{6}{|l|}{ Age } \\
\hline$<45$ years & $48(57.1 \%)$ & $36(42.9 \%)$ & 84 & \multirow[t]{2}{*}{0.111} & \multirow[t]{2}{*}{$\chi^{2}$} \\
\hline$\geq 45$ years & $13(40.6 \%)$ & $19(59.4 \%)$ & 32 & & \\
\hline \multicolumn{6}{|l|}{ Stage T } \\
\hline $\mathrm{T} 1+\mathrm{T} 2$ & $53(54.1 \%)$ & $8(44.4 \%)$ & 98 & \multirow[t]{2}{*}{0.452} & \multirow[t]{2}{*}{$\chi^{2}$} \\
\hline $\mathrm{T} 3+\mathrm{T} 4$ & $45(45.9 \%)$ & $10(55.6 \%)$ & 18 & & \\
\hline \multicolumn{6}{|l|}{ Stage N } \\
\hline No & $35(54.7 \%)$ & $29(45.3 \%)$ & 64 & \multirow[t]{2}{*}{0.615} & \multirow[t]{2}{*}{$\chi^{2}$} \\
\hline N1 & $26(50.0 \%)$ & $26(50.0 \%)$ & 52 & & \\
\hline \multicolumn{6}{|l|}{ Stage M } \\
\hline Presence & $1(33.3 \%)$ & $2(66.7 \%)$ & 3 & \multirow[t]{2}{*}{0.144} & \multirow[t]{2}{*}{$\chi^{2}$} \\
\hline Absence & $60(53.1 \%)$ & $53(46.9 \%)$ & 113 & & \\
\hline \multicolumn{6}{|c|}{ Extrathyroidal extension } \\
\hline Presence & $30(42.9 \%)$ & $40(57.1 \%)$ & 70 & \multirow[t]{2}{*}{$0.010^{*}$} & \multirow[t]{3}{*}{$\chi^{2}$} \\
\hline Absence & $28(68.3 \%)$ & $13(31.7 \%)$ & 41 & & \\
\hline Not report & & & & & \\
\hline \multicolumn{6}{|c|}{ V600E $B R A F$ mutation } \\
\hline Positive & $32(43.2 \%)$ & $42(56.8 \%)$ & 74 & \multirow{2}{*}{$0.007^{*}$} & \multirow[t]{2}{*}{$\chi^{2}$} \\
\hline Negative & $29(69.05 \%)$ & $13(30.95 \%)$ & 42 & & \\
\hline
\end{tabular}

*Statistically significant association. PTC = papillary thyroid carcinoma.

\section{Associations between BRAF V600E mutation and PTC clinical and pathological aspects}

Table 2 presents the investigated associations between PTC clinical and pathological aspects and BRAF V600E mutation in the PTC study group. According to the results, except for the association between the BRAF V600E mutation and BRAF protein overexpression, no significant association was further demonstrated between the analyzed aspects. However, most of the patients harboring the BRAF V600E mutation showed worse prognosis factors such as stage T3/T4 (61.1\%), lymph node (71.2\%), or distant metastasis (66.7\%), and extrathyroidal extension (68.6\%).

\begin{tabular}{|c|c|c|c|c|c|}
\hline Criteria & $\mathrm{V} 600 \mathrm{E}(+)$ & V600E (-) & $\mathrm{N}$ & $\mathrm{P}$ & Test \\
\hline \multicolumn{6}{|l|}{ Gender } \\
\hline Female & $58(65.9 \%)$ & $30(34.1 \%)$ & 88 & \multirow[t]{2}{*}{0.400} & \multirow[t]{2}{*}{$\chi^{2}$} \\
\hline Male & $16(57.1 \%)$ & $12(42.9 \%)$ & 28 & & \\
\hline \multicolumn{6}{|l|}{ Age } \\
\hline$<45$ years & $51(60.7 \%)$ & $33(39.3 \%)$ & 84 & \multirow[t]{2}{*}{0.264} & \multirow[t]{2}{*}{$\chi^{2}$} \\
\hline$\geq 45$ years & $23(71.9 \%)$ & $9(28.1 \%)$ & 32 & & \\
\hline \multicolumn{6}{|l|}{ Stage T } \\
\hline $\mathrm{T} 1+\mathrm{T} 2$ & $63(65.3 \%)$ & $35(34.7 \%)$ & 98 & \multirow[t]{2}{*}{0.797} & \multirow[t]{2}{*}{$\chi^{2}$} \\
\hline $\mathrm{T} 3+\mathrm{T} 4$ & $11(61.1 \%)$ & $7(38.9 \%)$ & 18 & & \\
\hline \multicolumn{6}{|l|}{ Stage N } \\
\hline No & $37(57.8 \%)$ & $27(42.2 \%)$ & 64 & \multirow[t]{2}{*}{0.137} & \multirow[t]{2}{*}{$\chi^{2}$} \\
\hline N1 & $37(71.2 \%)$ & $15(28.8 \%)$ & 52 & & \\
\hline \multicolumn{6}{|l|}{ Stage M } \\
\hline Presence & $2(66.7 \%)$ & $1(33.3 \%)$ & 3 & \multirow{2}{*}{0.916} & \multirow[t]{2}{*}{$\chi^{2}$} \\
\hline Absence & $72(63.7 \%)$ & $41(36.3 \%)$ & 113 & & \\
\hline \multicolumn{6}{|c|}{ Extrathyroidal extension } \\
\hline Presence & $48(68.6 \%)$ & $22(31.4 \%)$ & 70 & \multirow[t]{3}{*}{0.416} & \multirow[t]{3}{*}{$\chi^{2}$} \\
\hline Absence & $25(60.9 \%)$ & $16(39.1 \%)$ & 41 & & \\
\hline Not reported (5) & & & & & \\
\hline \multicolumn{6}{|l|}{ BRAF expression } \\
\hline$<50 \%$ & $32(52.4 \%)$ & $29(47.6 \%)$ & 74 & \multirow[t]{2}{*}{$0.008^{*}$} & \multirow[t]{2}{*}{$\chi^{2}$} \\
\hline$\geq 50 \%$ & $42(76.4 \%)$ & $13(23.6 \%)$ & 42 & & \\
\hline
\end{tabular}

*Statistically significant association. PTC = papillary thyroid carcinoma. 


\section{DISCUSSION}

In this study, a significant association between BRAF V600E mutation and BRAF protein overexpression was demonstrated in PTC. Such association might represent an important event in PTC carcinogenesis, although the molecular mechanisms involved in the control of BRAF expression and the stability of the BRAF protein remain unknown (Dantas et al., 2009; Koperek et al., 2012).

BRAF plays an important role in the RAS-RAF signaling cascade, a cellular pathway that controls normal cell growth, differentiation, and survival (Cox and Der, 2003). Several recent studies have established the important association of the BRAF V600E mutation in PTC prognosis (Xing et al., 2005; Lupi et al., 2007; Basolo et al., 2010; O’Neill et al., 2010; Capper et al., 2011; McKelvie et al., 2013). The V600E mutation results in a constitutively activated BRAF protein with a gain of function, independent of activator signals, and leading to continuous activation of the MAPK pathway, which may in turn result in the development of thyroid malignancies (Davies et al., 2002; Tang and Lee, 2010). Despite many studies evaluating the prognostic significance of the BRAF V600E mutation in human tumors, the precise molecular mechanism involved in BRAF V600E-associated carcinogenesis is still undetermined. It has been suggested that the BRAF V600E variant might affect gene methylation, thus silencing tumor suppressor genes by hypermethylation or activating oncogenes through hypomethylation (Hou et al., 2011).

The expression of the BRAF protein is of important clinical interest, particularly in the case of resistance to conventional therapy. In addition, BRAF immunostaining has already been suggested to be an important diagnostic tool in fine-needle aspirations of thyroid nodules, improving PTC diagnosis (Khan et al., 2014; Rossi et al., 2014; Zimmermann et al., 2014).

Molecular alterations associated with gene dysfunction and/or overexpression are crucial mechanisms involved in carcinogenesis. Therefore, overexpression of pivotal proteins may function as molecular markers for prediction of a more aggressive behavior (Capper et al., 2011). In the present study, a significant association was observed between BRAF protein expression and extrathyroidal extension of the tumor $(\mathrm{P}=0.0111)$, which represents a worse prognosis. BRAF overexpression was observed in PTC from older patients $(59.4 \%)$, and in those with more advanced stage PTC (55.6\%) and with distant metastasis (66.7\%); however, such associations were not statistically significant, likely due to the limited size of our sample.

Recently, a few studies have also investigated the prognostic value of BRAF protein expression and V600E mutation in PTC tumors using immunohistochemistry (Kondo et al., 2007; Capper et al., 2011; Feng et al., 2011; Koperek et al., 2012; McKelvie et al., 2013). In one of these (Feng et al., 2011), it was demonstrated that BRAF expression in PTC was significantly higher in tumors than in benign thyroid lesions. Among the PTC samples, BRAF protein detection was higher in the group with lymph node metastases, but the BRAF V600E mutation was not investigated. In that study, the same BRAF antibody employed for the immunohistochemistry analysis was that used herein (clone F-7, Santa Cruz Biotechnology Inc.). This study highlighted the importance of immunohistochemistry for the detection of the BRAF protein, by demonstrating its overexpression in the PTC group associated with worse prognosis. In contrast, Kondo et al. (2007) did not find a significant association between BRAF protein overexpression and V600E mutation; however, a different polyclonal antibody (sc-9002) was used for BRAF detection. 
A specific monoclonal antibody (VE1 clone) targeting the mutated form of the BRAF protein (V600E BRAF) has been used in several recent studies (Capper et al., 2011; Koperek et al., 2012; McKelvie et al., 2013) in order to distinguish the expression of the wild-type and the mutated BRAF proteins. It is possible that this BRAF antibody might facilitate the use of BRAF molecular analysis for diagnosis, particularly in patients with uncertain diagnosis or with insufficient material for molecular analyses, or even as a surrogate for genetic testing in clinical decisions (Capper et al., 2011; Koperek et al., 2012). The VE1 antibody demonstrates high sensitivity in paraffin sections and may represent the new gold standard for the detection of the BRAF V600E mutation in PTC (Bullock et al., 2012; McKelvie et al., 2013; Routhier et al., 2013).

Significant associations between the BRAF V600E mutation and clinicopathological characteristics of PTC have been reported in different studies (Salvatore et al., 2006; Xing, 2010). Two meta-analyses showed statistically significant associations between the mutation status and the characteristics of more aggressive tumors (Lee et al., 2007; Li et al., 2012b). Another study also found a significant association between this mutation and a smaller tumor size, indicating that the mutation might occur in the earlier stages of the disease (Xing et al., 2005).

The strong association between PTC and BRAF V600E mutation is well described, as is its association with poor prognosis (Lupi et al., 2007; Elisei et al., 2012; Guerra et al., 2012). According to our results, the BRAF V600E mutation was more frequent in older patients $(71.9 \%)$, and in those with more advanced tumor stages $(61.1 \%)$, lymph nodal $(71.2 \%)$ or distant metastasis (66.7\%), and extrathyroidal extension (68.6\%); however, significant statistical differences were not detected for the group. Many studies have demonstrated associations between the BRAF V600E mutation and metastasis in PTC (Xing et al., 2005; Lupi et al., 2007; Nakayama et al., 2007; Frasca et al., 2008; Basolo et al., 2010; Kurtulmus et al., 2012). Paradoxically, other studies were not able to corroborate such an association (Kwak et al., 2009; Hwang et al., 2010; Lee and Soh, 2010; Ahn et al., 2012). This discrepancy might be explained by the limited size of the samples studied and the use of different detection methods.

The main limitation of our study was the impossibility of following up the selected patients. Many began treatment at Araújo Jorge Hospital but did not return for follow-up. Clinical decisions after surgery were not recorded in medical records, disabling clinical follow-up or access to accurate information regarding the development of distant metastases after surgery, recurrence data, and other factors associated with poor prognosis.

In order to more accurately elucidate the prognostic role of the BRAF protein in PTC, investigation of a larger number of PTC samples, as well as a significant number of metastatic cases are recommended. We also suggest the development of functional studies in order to elucidate the molecular mechanisms involved in the control of $B R A F$ gene expression and the connection of cellular events concerned with the stabilization and degradation of the BRAF protein. Epigenetic mechanisms, through which the BRAF mutation drives carcinogenesis and pathogenesis in PTC, also need to be elucidated.

This is the first Brazilian study to investigate the association between BRAF protein expression, the BRAF V600E mutation, and clinicopathological aspects of PTCs. The present study demonstrated a significant association between the BRAF V600E mutation and BRAF protein overexpression, highlighting the importance of these molecular events in the process of PTC carcinogenesis. 


\section{ACKNOWLEDGMENTS}

Research supported by FAPEG (Fundação de Amparo à Pesquisa do Estado de Goiás).

\section{REFERENCES}

Ahn D, Park JS, Sohn JH, Kim JH, et al. (2012). BRAF V600E mutation does not serve as a prognostic factor in Korean patients with papillary thyroid carcinoma. Auris Nasus Larynx 39: 198-203.

American Thyroid Association (ATA) Guidelines Taskforce on Thyroid Nodules and Differentiated Thyroid Cancer, Cooper DS, Doherty GM, Haugen BR, et al. (2009). Revised American Thyroid Association management guidelines for patients with thyroid nodules and differentiated thyroid cancer. Thyroid 19: 1167-1214.

Basolo F, Torregrossa L, Giannini R, Miccoli M, et al. (2010). Correlation between the BRAF V600E mutation and tumor invasiveness in papillary thyroid carcinomas smaller than 20 millimeters: analysis of 1060 cases. J. Clin. Endocrinol. Metab. 95: 4197-4205.

Brose MS, Troxel AB, Redlinger M, Harlacker K, et al. (2009). Effect of BRAF V600E on response to sorafenib in advanced thyroid cancer patients. J. Clin. Oncol. 27: 15S

Bullock M, O'Neill C, Chou A, Clarkson A, et al. (2012). Utilization of a MAB for BRAF (V600E) detection in papillary thyroid carcinoma. Endocr. Relat. Cancer 19: 779-784.

Capper D, Preusser M, Habel A, Sahm F, etal. (2011). Assessment of BRAF V600E mutation status by immunohistochemistry with a mutation-specific monoclonal antibody. Acta Neuropathol. 122: 11-19.

Cohen Y, Xing M, Mambo E, Guo Z, et al. (2003). BRAF mutation in papillary thyroid carcinoma. J. Natl. Cancer Inst. 95: 625-627.

Cox AD and Der CJ (2003). The dark side of Ras: regulation of apoptosis. Oncogene 22: 8999-9006.

Dantas ELR, Sá FHL, de Carvalho SMF, Arruda AP, et al. (2009). Genética do câncer hereditário. Rev. Bras. Cancerol. 55: 263-269.

Davies H, Bignell GR, Cox C, Stephens P, et al. (2002). Mutations of the BRAF gene in human cancer. Nature 417: 949-954.

Elisei R, Viola D, Torregrossa L, Giannini R, et al. (2012). The BRAF (V600E) mutation is an independent, poor prognostic factor for the outcome of patients with low-risk intrathyroid papillary thyroid carcinoma: single-institution results from a large cohort study. J. Clin. Endocrinol. Metab. 97: 4390-4398.

Feng L, Li M, Zhang QP, Piao ZA, et al. (2011). Utility of BRAF protein overexpression in predicting the metastasis potential of papillary thyroid carcinoma. Oncol. Lett. 2: 59-63.

Frasca F, Nucera C, Pellegriti G, Gangemi P, et al. (2008). BRAF (V600E) mutation and the biology of papillary thyroid cancer. Endocr. Relat. Cancer 15: 191-205.

Gheriani H (2006). Update on epidemiology classification, and management of thyroid cancer. Libyan J. Med. 1: 83-95.

Guerra A, Fugazzola L, Marotta V, Cirillo M, et al. (2012). A high percentage of BRAF V600E alleles in papillary thyroid carcinoma predicts a poorer outcome. J. Clin. Endocrinol. Metab. 97: 2333-2340.

Hou P, Liu D and Xing M (2011). Genome-wide alterations in gene methylation by the BRAF V600E mutation in papillary thyroid cancer cells. Endocr. Relat. Cancer 18: 687-697.

Hwang J, Shin JH, Han BK, Ko EY, et al. (2010). Papillary thyroid carcinoma with BRAFV600E mutation: sonographic prediction. AJR Am. J. Roentgenol. 194: W425-W430.

Khan MS, Pandith AA, Azad N, Hussain MU, et al. (2014). Impact of molecular alterations of BRAF in the pathogenesis of thyroid cancer. Mutagenesis 29: 131-137.

Kondo T, Nakazawa T, Murata S, Kurebayashi J, et al. (2007). Enhanced B-Raf protein expression is independent of V600E mutant status in thyroid carcinomas. Hum. Pathol. 38: 1810-1818.

Koperek O, Kornauth C, Capper D, Berghoff AS, et al. (2012). Immunohistochemical detection of the BRAF V600Emutated protein in papillary thyroid carcinoma. Am. J. Surg. Pathol. 36: 844-850.

Kurtulmus N, Duren M, Ince U, Cengiz Yakicier M, et al. (2012). BRAF (V600E) mutation in Turkish patients with papillary thyroid cancer: strong correlation with indicators of tumor aggressiveness. Endocrine 42: 404-410.

Kwak JY, Kim EK, Chung WY, Moon HJ, et al. (2009). Association of BRAF V600E mutation with poor clinical prognostic factors and US features in Korean patients with papillary thyroid microcarcinoma. Radiology 253: 854-860.

Lee J and Soh EY (2010). Differentiated thyroid carcinoma presenting with distant metastasis at initial diagnosis clinical outcomes and prognostic factors. Ann. Surg. 251: 114-119.

Lee JH, Lee ES and Kim YS (2007). Clinicopathologic significance of BRAF V600E mutation in papillary carcinomas of the thyroid: a meta-analysis. Cancer 110: 38-46. 
Li C, Lee KC, Schneider EB and Zeiger MA (2012a). BRAF V600E mutation and its association with clinicopathological features of papillary thyroid cancer: a meta-analysis. J. Clin. Endocrinol. Metab. 97: 4559-4570.

Li X, Abdel-Mageed AB and Kandil E (2012b). BRAF mutation in papillary thyroid carcinoma. Int. J. Clin. Exp. Med. 5: 310-315.

Lupi C, Giannini R, Ugolini C, Proietti A, et al. (2007). Association of BRAF V600E mutation with poor clinicopathological outcomes in 500 consecutive cases of papillary thyroid carcinoma. J. Clin. Endocrinol. Metab. 92: 4085-4090.

McKelvie PA, Chan F, Yu Y, Waring P, et al. (2013). The prognostic significance of BRAF V600E mutation in papillary thyroid carcinoma detected by mutation-specific immunohistochemistry. Pathology 45: 637-644.

Nakayama H, Yoshida A, Nakamura Y, Hayashi H, et al. (2007). Clinical significance of BRAF (V600E) mutation and Ki-67 labeling index in papillary thyroid carcinomas. Anticancer Res. 27: 3645-3649.

O'Neill CJ, Bullock M, Chou A, Sidhu SB, et al. (2010). BRAF (V600E) mutation is associated with an increased risk of nodal recurrence requiring reoperative surgery in patients with papillary thyroid cancer. Surgery 148: 1139-1145.

Rossi ED, Martini M, Capodimonti S, Cenci T, et al. (2014). Analysis of immunocytochemical and molecular BRAF expression in thyroid carcinomas: A cytohistologic institutional experience. Cancer Cytopathol. 122: 527-535.

Routhier CA, Mochel MC, Lynch K, Dias-Santagata D, et al. (2013). Comparison of 2 monoclonal antibodies for immunohistochemical detection of BRAF V600E mutation in malignant melanoma, pulmonary carcinoma, gastrointestinal carcinoma, thyroid carcinoma, and gliomas. Hum. Pathol. 44: 2563-2570.

Salvatore G, De Falco V, Salerno P, Nappi TC, et al. (2006). BRAF is a therapeutic target in aggressive thyroid carcinoma. Clin. Cancer Res. 12: 1623-1629.

Sipos JA and Mazzaferri EL (2010). Thyroid cancer epidemiology and prognostic variables. Clin. Oncol. 22: 395-404.

Tang KT and Lee CH (2010). BRAF mutation in papillary thyroid carcinoma: pathogenic role and clinical implications. J. Chin. Med. Assoc. 73: 113-128.

Vidwans SJ, Flaherty KT, Fisher DE, Tenenbaum JM, et al. (2011). A melanoma molecular disease model. PLoS One 6: e18257.

Wojciechowska K and Lewinski A (2006). BRAF mutations in papillary thyroid carcinoma. Endocr. Regul. 40: 129-138.

Xing M (2010). Prognostic utility of BRAF mutation in papillary thyroid cancer. Mol. Cell. Endocrinol. 321: 86-93.

Xing M, Westra WH, Tufano RP, Cohen Y, et al. (2005). BRAF mutation predicts a poorer clinical prognosis for papillary thyroid cancer. J. Clin. Endocrinol. Metab. 90: 6373-6379.

Zimmermann AK, Camenisch U, Rechsteiner MP, Bode-Lesniewska B, et al. (2014). Value of immunohistochemistry in the detection of BRAF (V600E) mutations in fine-needle aspiration biopsies of papillary thyroid carcinoma. Cancer Cytopathol. 122: 48-58. 